\title{
Import-mixing sorbents for purification of waste production water of gas processing industry for re-use.
}

\author{
Yusupov Farkhod,Nuriddinova Dilfuza,Yakhsheva Yulduz, \\ Yusupov Sukhrob,Mamanazarov Murodali
}

\author{
Institute of General and Inorganic Chemistry Academy of Sciences Republic of \\ Uzbekistan,
}

St.Mirzo Ulugbek 77a, Tashkent city 100170,Uzbekistan

Received: November 14, 2020. Revised: May 23, 2021. Accepted: June 17, 2021. Published: June 29, 2021.

\begin{abstract}
-currently, there are a variety of methods and technologies for water purification. One of them is the adsorption method. Today the adsorption method is widely used in the water treatment industry.

The aim of the research is to create an effective multifunctional filtering composition suitable for complex physical and chemical water purification. For this, a cation exchanger developed on the basis of local raw materials, activated alumina and other local materials was used.
\end{abstract}

The adsorption properties of the cation exchanger and aluminum oxide in the composition of this filter have been studied.

Also, the parameters of the filter for water purification are determined.

Key words: sorbent, sorption, water hardness, aluminum oxide,ion exchanger.

\section{INTRODUCTION}

Rational water use is one of the priority areas in the field of environmental protection. The rapidly growing demand for water and the limited supply of water, along with the rise in the cost of water treatment processes, lead to the need to create new technologies for water treatment. The quality of water acts as a characteristic of its composition and properties, which

determines its suitability for specific types of water use. One of the important indicators of the quality of water, regulated by regulatory documents when using it for household and drinking or technical needs of various industries, is the indicator of the total hardness of water. Reducing the hardness of calcium or magnesium ions in water is very important in solving this problem. The concentration of hardness of waste water $1 \mathrm{Mg}$-eq / 1 is equal to $20.04 \mathrm{mg}$ of $\mathrm{Ca} 2+$ ions or $12.16 \mathrm{mg}$ of $\mathrm{Mg} 2+$ ions, which corresponds to the requirement of reuse of purified water at the workplace. In industry, water hardness exceeds $12-17 \mathrm{mg}$-eq / 1 . The minimum hardness standard is $1.6-3.0 \mathrm{mg} / \mathrm{eq}$ $/ 1$ according to (SANPIN 2.1.4.1116-02) "Drinking water - hygienic requirements for the quality of bottled water - quality control" (Russian Federation) [1-2].Practical results show that when the concentration of $\mathrm{Ca} 2+$ or $\mathrm{Mg} 2+$ ions increases the amount of accumulated sludge in water pipes, heat exchangers and household appliances in plumbing facilities, it also increases. A high concentration of $\mathrm{Ca} 2+$ or $\mathrm{Mg} 2+$ ions covers the metal surface in the form of salt deposits: $\mathrm{CaCl} 2, \mathrm{CaSO} 4, \mathrm{MgCl} 2$, $\mathrm{MgSO} 4, \mathrm{CaCO} 3$ and $\mathrm{MgCO} 3$. The accumulated sediment salts on the metal surface cause corrosion of metal materials. A low concentration of metal ions $(0.5 \mathrm{mEq} / \mathrm{L})$ is corrosive, which means that metal materials have been destroyed. In these processes, metal ions with a low concentration have a corrosive effect on corrosion reactions that require the activity of iron ions, and a low concentration of $\mathrm{Ca} 2+$ or $\mathrm{Mg} 2+$ ions can increase the degree of activity of iron ions [3-6].Industrial waste waters of oil and gas enterprises are complex systems containing mineral and organic substances, the composition and amount of which is usually determined by the nature of technological processes. Pollution can be in water in the form of suspended particles of various sizes (dispersed systems suspensions and colloidal solutions) and in a truly dissolved state. The authors $[1,2,16]$ described the problems of water purification from impurities, which must be done. This requires a change in the composition of the source water: 
- present in the form of dissolved bivalent, undissolved trivalent (iron hydroxides) and organic (complexes of ferrous and trivalent iron with humic substances of natural origin - with humic and fulvic acids) iron compounds.

- compounds of divalent manganese.

- heavy metals, in cationic and non-cationic forms. -calcium and magnesium salts of hardness, mainly in the form of hydrocarbons, as well as chlorides and sulfates.

- suspended solids, suspensions of undissolved ferric iron (iron hydroxides) of various dispersion (from 1-3 to 20-50 microns), as well as sand and clay of natural origin. Impurities with a fineness of less than 1 micron can exist in the form of colloids. - humic substances of natural origin (humic and fulvic acids, their water-soluble salts and insoluble salts in the form of colloids);

- increased turbidity of water, mainly caused by impurities;

- $\mathrm{pH}$ value is less than 6-6.5 units (increased acidity of water) [3.4].

There are various methods and technologies for water purification, which can partially solve the listed problems, using sorption-filter media $[5,6,15]$.

The currently used filter for water purification, which contains a housing with a floating load, a distribution system, a means for automatic switching of the filter operation mode, is equipped with a pocket with a multifunctional filtering composition - soaked in sorption or ion-exchange material from expanded polystyrene granules, which automatically enters the floating load along inclined trays at the end of the filter washing process, a container for receiving spent sorption or ion-exchange material, a floating container that serves to charge and activate the siphon, and the upper part of the descending branch of the siphon is connected by a tube to a container for receiving washing water, in which a float is placed, regulating lifting and lowering the gate on the supply of sorption or ion-exchange material to inclined trays $[7,8]$.

Low efficiency of use and narrowness of functionality are the disadvantages of this technical solution. Water purification from a limited amount of impurities is carried out mechanically, where only large particles are captured, it is impossible to adjust the $\mathrm{pH}$ of the purified water.
The creation of an effective filter is the main task of the study, which is suitable for the complex physicochemical purification of water in one device, as well as for the regulation of acidity $[9,10,14]$.

\section{METHODOLOGY}

The cation exchanger is obtained by modification with sulfuric acid on the basis of local PVC waste. The modification reaction of granular PVC plasticate is carried out in a reactor, by the interaction of a certain amount of granular PVC plasticate with sulfuric acid, the reaction is carried out at a temperature of $100-130^{\circ} \mathrm{C}$ for 1 3 hours.

The sorption of a metal ion was studied to determine the sorption capacity of the obtained sorbent. The sorption process was studied from solutions with different concentrations of $\mathrm{Ca} 2+$ and $\mathrm{Mg} 2+$ ions. The titrimetric method was used to determine the amount of metal ions before and after sorption.

Table 1. Filter composition (\%)

\begin{tabular}{|l|l|l|}
\hline $\mathbf{1}$ & $\begin{array}{l}\text { Polystyrene } \\
\text { granules }\end{array}$ & $15-20$ \\
\hline $\mathbf{2}$ & $\begin{array}{l}\text { Anionite } \\
\text { layer }\end{array}$ & $20-25$ \\
\hline $\mathbf{3}$ & $\begin{array}{l}\text { Cation } \\
\text { exchange } \\
\text { layer }\end{array}$ & $40-45$ \\
\hline $\mathbf{4}$ & $\begin{array}{l}\text { Bentonite, } \\
\text { aluminum } \\
\text { oxide }\end{array}$ & $10-15$ \\
\hline $\mathbf{5}$ & Sand & $4-6$ \\
\hline $\mathbf{6}$ & Calcite & $4-6$ \\
\hline
\end{tabular}

$\mathrm{K}$ - correction factor for bringing the solution of trilon B to $0.05 \mathrm{M}$;

$\mathrm{V}$ is the volume of the original sample, $\mathrm{ml}$;

$\mathrm{E}$ is the equivalent of magnesium and calcium ions (24.31 and 40.08, respectively).

The value of the specific sorption $\mathrm{X} / \mathrm{m}$ was calculated according to the formula:

$\frac{\Delta \mathrm{X}}{\mathrm{m}}=\frac{\left(\mathrm{C}_{0}-\mathrm{C}_{\tau}\right) \cdot \mathrm{V}}{\mathrm{M} \cdot \mathrm{m}}$

$\mathrm{X}$ - number of sorbed ions, mole. 
$\mathrm{m}$ - mass of sorbent, $\mathrm{g}$.

$\mathrm{C}_{0}$ and $\mathrm{C}_{\tau}-$ concentration of ions in solution before and after adsorption, $\mathrm{g} / \mathrm{l}$.

$\mathrm{V}$ - volume of solution, 1 .

$\mathrm{M}$ - molecular mass of ions, $\mathrm{g} / \mathrm{mol}$.

To determine the dynamic exchange capacity (DEC) of fibrous ion-exchange sorbents, the ionexchanger was loaded into the ion-exchange column and the test solution was passed through the ion exchanger layer until the concentration of the ion in the initial and discharged solutions was expressed. The dynamic exchange capacity of the sorbent was calculated using the formula.

$D O E=\frac{V \cdot C}{g}$

$\mathrm{V}$ is the volume of the passed solution, $\mathrm{ml}$;

$\mathrm{C}$-concentration of $\mathrm{CuSO} 4$ solution $\mathrm{mg} / \mathrm{l}$; $\mathrm{g}$ is the mass of the sorbent, g.

\section{RESULTS AND DISCUSSIONS}

The essence of the research is that the filter contains

layers arranged in ascending order of the true density of materials, and includes a filtering layer of a polymer material with a density of less than 1 $\mathrm{g} / \mathrm{cm} 3$, an anionite layer, a cationite layer and layers of distribution-filtering materials with the layers located on top down in the following sequence and with the following content of components in \%:

Table 1. Filter composition (\%)

\begin{tabular}{|l|l|l|}
\hline Sample & $\begin{array}{l}\text { nitial conc., } \\
\mathrm{mg} / 1\end{array}$ & Output conc., mg / 1 \\
\hline 1 & 1 & $0,02-0,40$ \\
\hline 2 & 1,5 & $0,03-0,40$ \\
\hline 3 & 2 & $0,03-0,45$ \\
\hline 4 & 2,5 & $0,04-0,50$ \\
\hline
\end{tabular}

The layer is a floating layer loaded with polyethylene or polystyrene granules with a size of $1.4-8 \mathrm{~mm}$. A layer of water is formed between the layers, because layer densities differ from each other.
The anion-resin layer is a layer of ion-exchange material with selective sorption capacity.

A layer of cation exchanger, mainly sulfonic cation exchanger in $\mathrm{Na}$ - or $\mathrm{K}$-form $(100 \%$ of the cation exchanger is in the Na-form, or $100 \%$ is in the $\mathrm{K}$-form). This layer is 2 times thicker than the rest of the layers.

A layer of aluminum oxide, bentonite is a fine layer for filtering particles, having a size of 3-5 microns and more.

The gravel layer is used to filter particles with a size of 20 microns and more Layer composition: $1-20 \%$ of filter material with a density of at least $1.4-2.5 \mathrm{~g} / \mathrm{cm} 3$ and a granule size of $1.5-8 \mathrm{~mm}$, which consists of the group: quartz sand, gravel, garnet (garnet), anthracite (hydroanthracite).

The calcite layer has $\mathrm{pH}$ adjusting properties, i.e. treatment of water with high acidity), with a granule size of $1.5-8 \mathrm{~mm}$.

On a layer with fine cleaning, filtration of particles larger than 3-5 microns is provided (that is, it acts as a fine filter). The adsorption-cohesive mechanism is used to filter particles with a developed rough surface of the material used.

Activated alumina is a promising sorbent for removing phosphorus from wastewater [11]. The granular sorbent of activated alumina was tested under dynamic conditions. Wastewater with an initial concentration of phosphate ions of 1.5-2.5 $\mathrm{mg} / 1$ was passed through the sorbent.

Table 2. Purification of phosphate ions by sorbent (aluminum oxide)

\begin{tabular}{|l|l|l|}
1 & 1 & $0,02-0,40$ \\
\hline 2 & 1,5 & $0,03-0,40$ \\
\hline Sample & nitial conc., mg / 1 & Output conc., mg / 1 \\
\hline 3 & 2 & $0,03-0,45$ \\
\hline 4 & 2,5 & $0,04-0,50$ \\
\hline
\end{tabular}

The distribution-filtering layer has the properties of adjusting the $\mathrm{pH}$ and provides filtration of suspended particles with a size of more than 20 microns, makes it possible to adjust the $\mathrm{pH}$, and allows to increase the hardness of the treated 
water. This is due to the dissolution of the material in a hydrocarbonate environment.

The content of each component may vary within the above limits; the specific composition depends on the quality of the treated water - on the content of removed impurities, and can be optimized in each specific case.

Salts - $\mathrm{Ca} 2+$ ', Mg2 +', partly Fe2 +, as well as $\mathrm{Mn} 2+$, ammonium and heavy metals in cationic form are absorbed onto the cation exchanger layer according to the following mechanism:

$$
2 \mathrm{RNa}+\mathrm{Ca}^{2+} \rightarrow \mathrm{R}_{2} \mathrm{Ca}+\mathrm{Na}^{+}
$$

$\mathrm{R}$-is an ion-exchange monovalent matrix of a cation exchanger without an exchange ion). Similar exchange reactions occur with the participation of other cations $-\mathrm{Mg} 2+$ ', $\mathrm{Fe} 2+$, $\mathrm{Mn} 2+, \mathrm{NH} 4+$. The layers that remove organic substances, iron and cations provide preliminary cleaning from suspended solids in the filtering layer 1 with a floating load $[12,13]$.

The sorption of $\mathrm{Ca} 2+$ ions with a filter was studied depending on the time, temperature, and concentration of $\mathrm{Ca} 2+$ ions in the initial solution. The results of these studies are shown in Fig. 1-4. As seen from fig. 1-4, the sorption equilibrium between the sorbent and the solution in all cases is set within 15 hours.

G gr- eq/g

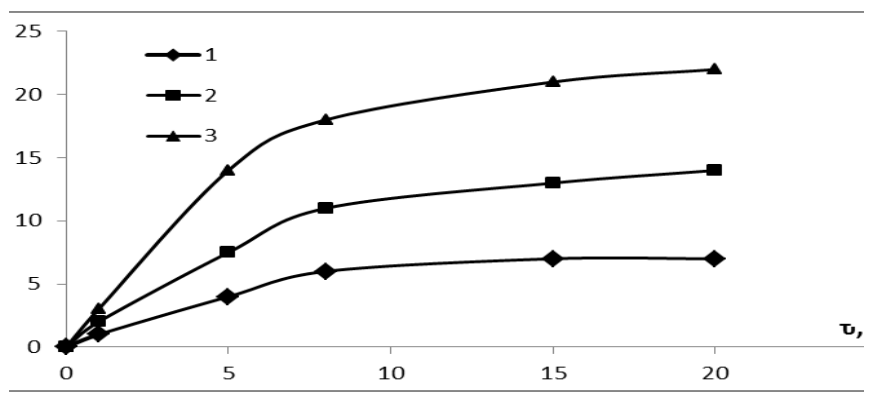

Time

Fig. 1. Kinetics of sorption of ions, calcium sorbent

1, 2, 3 - sorption temperatures 293, 303, $313 \mathrm{~K}$, respectively, $\mathrm{C}=0.02 \mathrm{H}$.

G gr- eq/g

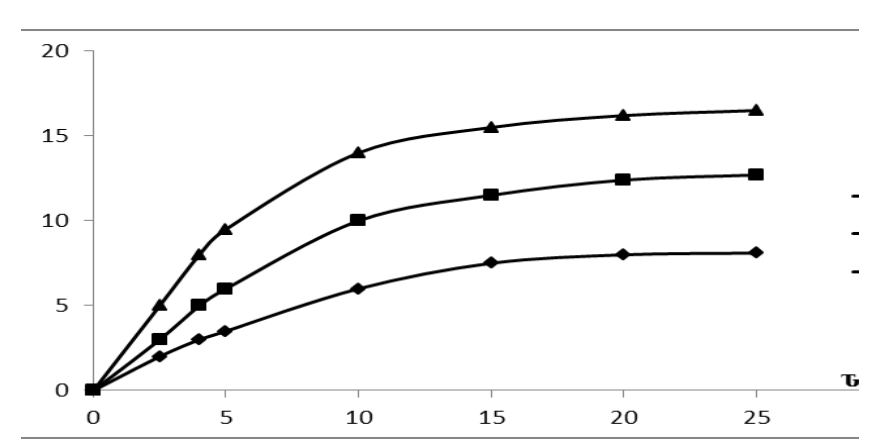

Time

Fig. 2. Kinetics of sorption of ions, calcium sorbent

1, 2, 3 - sorption temperatures $293,303,313 \mathrm{~K}$, respectively, $\mathrm{C}=0.03 \mathrm{H}$.

G gr- eq/g

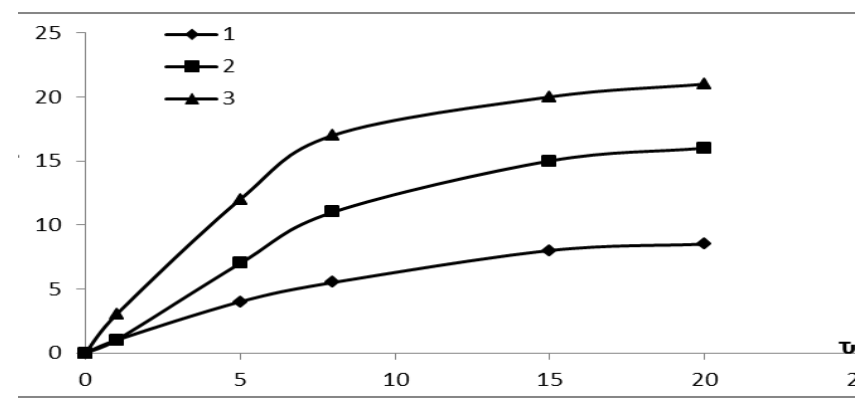

Time

Fig. 3. Kinetics of sorption of ions, calcium sorbent

1, 2, 3 - sorption temperatures $293,303,313 \mathrm{~K}$, respectively, $\mathrm{C}=0.04 \mathrm{H}$.

G gr- eq/g

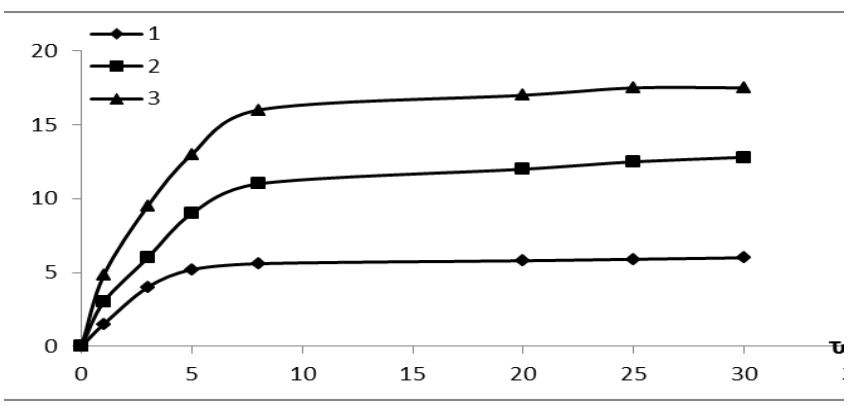

Time

Fig. 4. Kinetics of sorption of ions, calcium sorbent

1, 2, 3- sorption temperatures $293,303,313 \mathrm{~K}$, respectively, $\mathrm{C}=0.05 \mathrm{H}$ 
This image shows that the rate of sorption of calcium ions depends on the temperature and concentration of ions in the solution.

With an increase in the temperature of the process, a slight decrease in the specific sorption is observed, which, apparently, is explained by an increase in the movement of the compressed.

G gr- eq/g

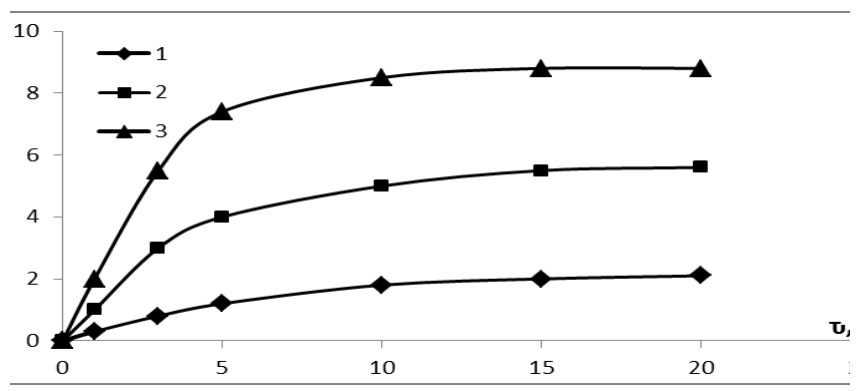

Time

Fig. 5. Kinetics of sorption of ions of magnesium with sorbent

$1,2,3$ - sorption temperatures $293,303,313 \mathrm{~K}$, respectively, $\mathrm{C}=0.02 \mathrm{H}$.

G gr- eq/g

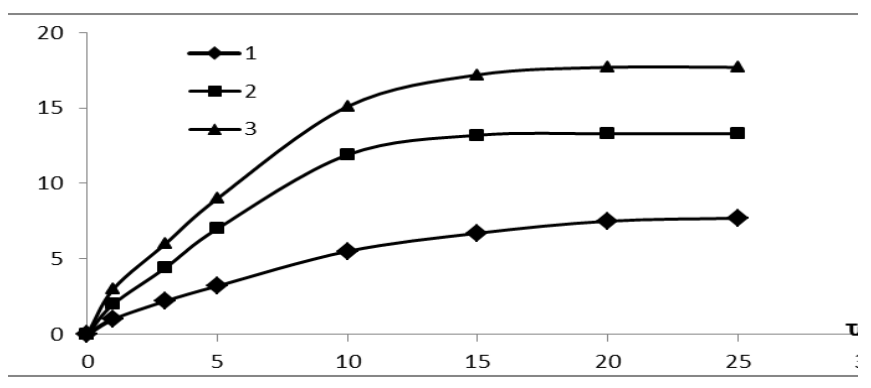

Time

Fig. 6. Kinetics of sorption of ions of magnesium with sorbent

1, 2, 3 - sorption temperatures $293,303,313 \mathrm{~K}$, respectively, $\mathrm{C}=0.03 \mathrm{H}$.

G gr- eq/g

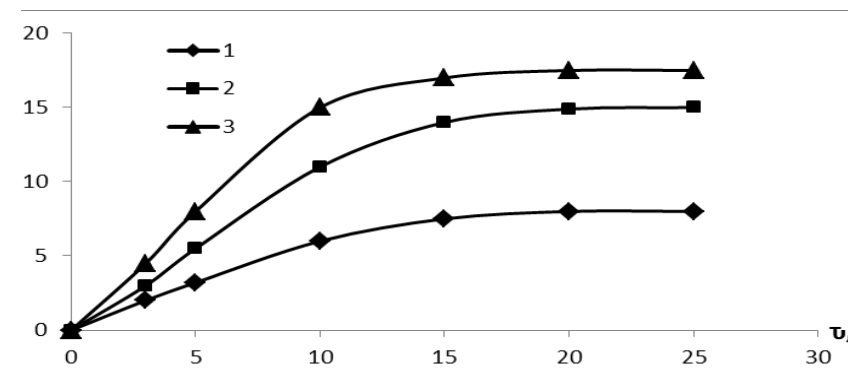

Time

Fig. 7. Kinetics of sorption of ions of magnesium with sorbent

1, 2, 3 - sorption temperatures 293, 303, $313 \mathrm{~K}$, respectively, $\mathrm{C}=0.04 \mathrm{H}$.

G gr- eq/g

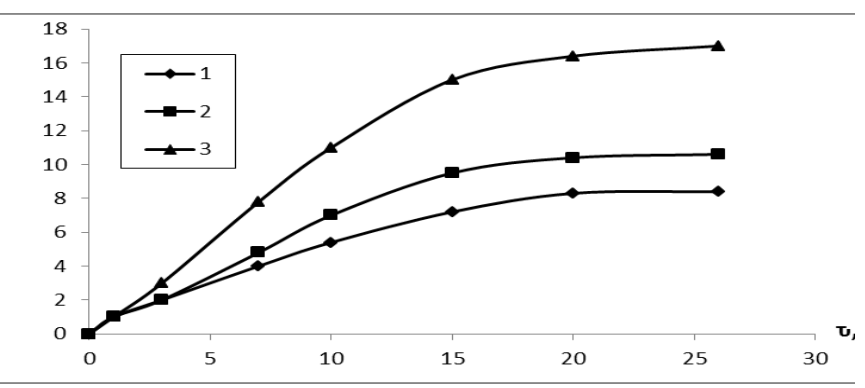

Time

Fig. 8. Kinetics of sorption of ions of magnesium with sorbent

1, 2, 3 - sorption temperatures $293,303,313 \mathrm{~K}$, respectively, $\mathrm{C}=0.05 \mathrm{H}$.

The sorption of magnesium ions by sorbent was studied as a function of time, temperature, and concentration of ions in the initial solution. The results of these studies are shown in Fig. 5-8. With an increase in the temperature of the process, a slight decrease in the specific sorption is observed, which, apparently, is explained by an increase in the movement of the compressed and Fig. Figures 9 and 10 show the isotherms of the sorption of calcium and magnesium ions by sorbent at different temperatures. It can be seen that an increase in the concentration of calcium ions, magnesium in the original solution and an increase in temperature leads to the growth of their sorption. This indicates that the process of handling is supported by the formation of chemical connections, i.e. it is a chemotherapy.

$\mathrm{G} \mathrm{mg/g}$ 


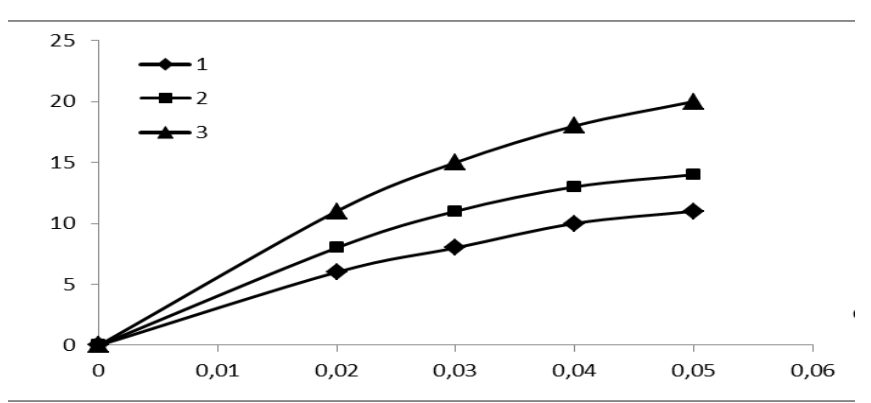

SR

Fig. 9. Isotherms of sorption of calcium ions by sorbent at different temperatures.

1, 2, 3 - sorption temperatures 293 (1), 303 (2), $313 \mathrm{~K}$ (3), respectively.

\section{$\mathrm{G} \mathrm{mg} / \mathrm{g}$}

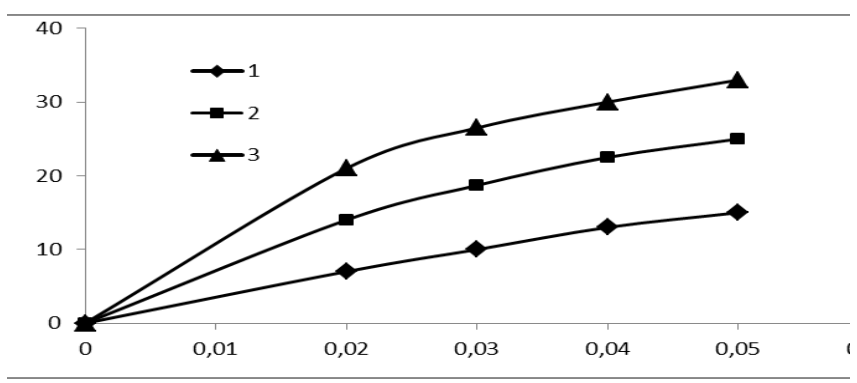

SR

Fig. 10. Isotherms of the sorption of magnesium ions by sorbent at different temperatures.

1, 2, 3 - sorption temperatures 293 (1), 303 (2), $313 \mathrm{~K}(3)$, respectively.

The tests carried out on several samples showed that using the proposed multifunctional filtering composition, water with high levels of contamination is purified; this removes contamination to very low levels. Table 1 shows the typical values of the concentration of impurities in the input water and water after treatment.

\section{Table 3. Results of water treatment}

According to the test results, it can be concluded that when using the proposed As can Can be seen from the table that the anionite layer in the created complex filter purifies water from such anions as $\mathrm{Cl}-$, SO42-. The cationic layer purified water from $\mathrm{Ca} 2+, \mathrm{Mg} 2+$ cations, as a result of which the water hardness decreased. The remaining layers of the filter mainly help to purify the water from various mechanical residues. As a result, purified water using this complex filter becomes usable. As a result of the research, an effective filter was created, which is suitable for complex water purification, acidity regulation as part of one device.multifunctional filtering composition, it is possible to achieve a high degree of water purification from impurities.

\section{CONCLUSION}

An effective filter was created, which is suitable for complex water purification, acidity regulation as part of one device.

The result obtained provides a solution to the urgent problem posed, which expands the functionality, improves consumer qualities, ensures environmental safety (without the use of strong oxidants - potassium permanganate, sodium hypochlorite, and therefore, there is no discharge during regeneration), and a decrease in the amount of waste. Most importantly, in one cleaning cycle, most unwanted impurities are removed.

The created filter uses cation exchangers obtained on the basis of local raw materials. It was found that this cation exchanger has good sorption properties and is effective for water purification from $\mathrm{Ca} 2+, \mathrm{Mg} 2+$. In the future, it is planned to study the localization of other components in the filter.

\section{ACKNOWLEDGEMENTS}

This work was supported by the scientific research program of General and Inorganic Chemistry Academy,Uzbekistan

\section{REFERENCES}

[1].B.N.Frog, A.P. Levchenko. "Water treatment". Moscow, 2003

[2]. B.E. Ryabchikov. "Modern methods of water preparation for industrial and domestic use." Moscow, 2004

[3]. A.S Kopylov, V.M Lavygin, V.F Ochkov. "Water treatment in power engineering". Moscow, 2003

[4]. R.U No. 2142317, 1997 
[5]. Nuriddinova D.Z., Yusupov, F.M. Cleaning water from oil products by carbon mineral sorbent. Volgograd 2018.p.8-11

[6]. W. Cao, Z. Dang, X.Q. Zhou, X.Y. Yi, P.X. $\mathrm{Wu}, \mathrm{N} . W$. Zhu, G.N. Lu, Removal of sulphate from aqueous solution using modified rice straw: preparation, characterization and adsorption performance, Carbohydr. Polym., 2011, vol. 85 p. 571.

[7].Chinese NEPA, Water and Wastewater Monitoring Methods, (fourth ed.), Chinese Environmental Science Publishing House, Beijing, China, 2012, p. 52.

[8].UNEP, Water and Wastewater Reuse. An Environmentally Sound Approach for Sustainable Urban Water Management., 2013, USA.

[9]. Kerrn-Jespersen J.P, Henze, M, Strube R (1994) Biological Phosphorus Release and Uptake Under Alternating Anaerobic and Anoxic Conditions in a Fixed-film Reactor. Water Research, vol. 28, 1994, p. 1253.

[10].Asatekin, A.M. Mayes, Oil industry wastewater treatment with fouling resistant membranes containing amphiphilic comb copolymers, Environ. Sci. Technol., Vol. 43, 2009, p. 4487.

[11].P.D. Fletcher, L.D. Savory, F. Woods, A. Clarke, A.M. Howe, Model study of enhanced oil recovery by flooding with aqueous surfactant solution and comparison with theory, Langmuir, vol. 31, 2015, p. 3076.

[12]. Praveen K. Bayannavar, Madivalagouda S. Sannaikar, S. Madan Kumar, Sanjeev R. Inamdar, Saba Kauser J. Shaikh, Aravind R. Nesaragi, Ravindra R. Kamble, Synthesis, X-ray characterization, DFT studies and Hirshfeld surface analysis of new organic single crystal: 2(4-Methoxyphenyl) -4 - \{[2 '- (1H-tetrazol-5-yl) biphenyl-4-yl] methyl $\}$-2,4-dihydro-3H-1, 2,4triazol-3-one (MTBT), Journal of Molecular Structure, 2019, 1179: 809-819

[13]. Thammarat Aree, Suchada Jongrungruangchok, Structure - antioxidant activity relationship of $\beta$-cyclodextrin inclusion complexes with olive tyrosol, hydroxytyrosol and oleuropein: Deep insights from X-ray analysis, DFT calculation and DPPH assay, Carbohydrate Polymers, 2018, 199: 661-669.
[14].UNEP, Water and Wastewater Reuse. An Environmentally Sound Approach for Sustainable Urban Water Management., 2013, USA.

[15].Kerrn-Jespersen J.P, Henze, M, Strube R (1994) Biological Phosphorus Release and Uptake Under Alternating Anaerobic and Anoxic Conditions in a Fixed-film Reactor. Water Research, vol. 28, 1994, p.1253.

[16].Asatekin, A.M. Mayes, Oil industry wastewater treatment with fouling resistant membranes containing amphiphilic comb copolymers, Environ. Sci. Technol., vol. 43, 2009, p. 4487.

[17].P.D. Fletcher, L.D. Savory, F. Woods, A. Clarke, A.M. Howe, Model study of enhanced oil recovery by flooding with aqueous surfactant solution and comparison with theory, Langmuir, vol. 31, 2015, p. 3076.

[18].Praveen K. Bayannavar, Madivalagouda S. Sannaikar, S. Madan Kumar, Sanjeev R. Inamdar, Saba Kauser J. Shaikh, Aravind R. Nesaragi, Ravindra R. Kamble, Synthesis, X-ray characterization, DFT studies and Hirshfeld surface analysis of new organic single crystal: 2(4-Methoxyphenyl)-4- $\{[2 '-(1 \mathrm{H}-$ tetrazol-5-

yl)biphenyl-4-yl] methyl $\}$-2,4-dihydro-3H-1,2,4triazol-3-one (MTBT), Journal of Molecular Structure, 2019, 1179:809-819

[19]. Thammarat Aree, Suchada Jongrungruangchok, Structure-antioxidant activity relationship of $\beta$-cyclodextrin inclusion complexes with olive tyrosol, hydroxytyrosol and oleuropein: Deep insights from X-ray analysis, DFT calculation and DPPH assay, Carbohydrate Polymers, 2018, 199:661-669.

Creative Commons Attribution License 4.0 (Attribution 4.0 International, CC BY 4.0)

This article is published under the terms of the Creative

Commons Attribution License 4.0

https://creativecommons.org/licenses/by/4.0/deed. en US 